\title{
Anaesthesia and the child with HIV infection
}

Donald Schwartz MD, * Tina Schwartz RN MSN, $\dagger$

Ellen Cooper MD, $\ddagger$ John Pullerits MD FRCPC\$

The frequency of AIDS in the paediatric population is growing rapidly and is expected to get worse. The anaesthetist will participate in the care of these children in the operating room and the intensive care unit with increasing frequency and must therefore have an understanding of the many manifestations of this syndrome. Children become infected with HIV by transplacental transmission from mother to fetus in over $80 \%$ of cases. Early diagnosis in infants can be very difficult. Clinical manifestations of HIV infection in children result from damage to almost every organ system. Considerations for the anaesthetist include: the effects of medications, cardiovascular dysfunction, pulmonary disease, altered metabolism, equipment preparation, choice of anaesthetic, modes of viral transmission and psycho-social issues.

La fréquence du SIDA chez la population pédiatrique est en croissance et l'on ne s'attend pas à une diminution. L'anesthésiste participera aux soins de ces enfants en salle d'opération et aux soins intensifs de plus en plus fréquemment et doit ainsi comprendre les diverses manifestations de ce syndrome. Les enfants s'infectent avec le HIV par transmission transplacentaire dans plus de $80 \%$ des cas. Le diagnostic précoce chez les bébés peut être très difficile. Les manifestations cliniques de l'infection a l'HIV chez les enfants amènent des lésions dans presque tous les systèmes. Les considérations pour l'anesthésiste incluent : les effets de la médication, la dysfonction cardiovas-

\section{Key words}

ANAESTHESIA: paediatric;

INFECTION: AIDS, HIV.

From the Department of Anesthesiology,* Tufts Medical School and Baystate Medical Center, Springfield, Massachusetts; The Department of Nursing, $\uparrow$ Boston City Hospital, Boston, Massachusetts; The Department of Pediatrics, $\ddagger$ Boston University School of Medicine and Boston City Hospital, Boston, Massachusetts; and The Department of Anaesthesia, $\S$ Harvard Medical School and The Children's Hospital, Boston, Massachusetts.

Address correspondence 1o: Dr. Donald Schwartz, Departments of Anesthesiology and Pediatrics, Baystate Medical Center, Springfield, MA 01199 U.S.A.

Accepted for publication 13th February, 1991. culaire, les maladies pulmonaires, l'altération du métabolisme, la préparation de l'équipement, le choix de l'anesthésique, les modes de la iransmission virale et les problèmes psychosociaux.

Since the first cases of acquired immune deficiency syndrome (AIDS) were described in infants in 1982, the problem of paediatric AIDS has grown at an alarming rate. As of November 30, 1990, 2734 cases of AIDS in children have been reported to the Centers for Disease Control (CDC) in the United States. More than 3,000 cases are predicted in the US in 1991 with several thousand more children infected with HIV (human immunodeficiency virus) who do not yet meet the CDC criteria for AIDS. ${ }^{1,2}$ Worldwide, the numbers are staggering with estimates of several million affected children by the turn of the century. The frequency with which HIV-infected children present for surgical management is expected to increase. The paediatric anaesthetist can expect to care for these children in increasing numbers and must remain well informed about paediatric AIDS and its wide array of clinical manifestations.

Previous reviews on AIDS in the anaesthesia literature focused primarily on the risks of transmission of the virus, safety procedures and serological testing..$^{3-9}$ The purpose of this review is to highlight the clinical aspects of paediatric HIV infection, particularly those that are relevant to the management of these children in the operating room and the intensive care unit. Areas where the disease differs between children and adults will be emphasized.

A brief review of viral pathogenesis, modes of transmission in children and means of detection is basic to a complete understanding of the disease.

\section{Pathogenesis, epidemiology and serology}

AIDS is caused by a human T-lymphotropic retrovirus. As the virus replicates, T-lymphocytes are damaged or destroyed, leading to cell-mediated immunodeficiency. Defects in macrophages, monocytes, neutrophils and complement pathways have all been described. Abnormal immunological laboratory findings in the HIV-infected child are summarized in Table $\mathrm{I}^{10}$

"Pediatric AlDS" refers to a subgroup of children in- 
TABLE I Laboratory abnormalitics in symptomatic pacdiatric HIV infection

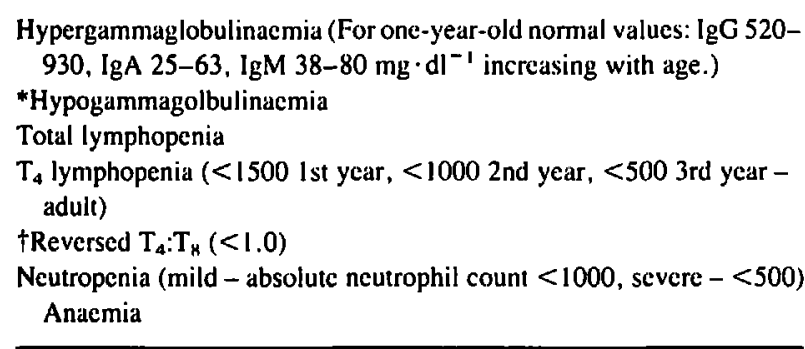

*Unusual in comparison to hypergammaglobulinacmia.

tOften a late manifestation.

fected with HIV who are $<13$ years old. Older adolescents run a clinical course which is indistinguishable from that of adults and for statistical purposes are grouped with them. Over $80 \%$ of HIV-infected children become so by transplacental exposure to maternal HIV during the perinatal period. This is usually a result of maternal iv drug abuse or heterosexual transmission. Children may also be exposed to the virus during blood transfusions ( $\approx 13 \%$ of cases) and from blood products for the treatment of coagulation disorders $(\approx 5 \%)$. $^{10}$

Infection with HIV in children can be determined by the isolation of virus particles or antigen in blood or tissues. The techniques for this (cell culture, etc.) are difficult and impractical in the clinical setting ("negative" results are hard to interpret). Hence indirect serological detection of antibody to HIV (by ELISA or Western Blot) is the method most commonly used.

Not all offspring of HIV-positive women are infected. Recent studies indicate that the transplacental transmission rate from mother to infant is approximately $30-40 \%$. Differentiating those infants who are infected with HIV from those who are not presents a difficult dilemma. During pregnancy, HIV maternal antibody is passively transferred across the placenta regardless of whether actual viral transmission occurs. All children born to HIV-positive mothers will have HIV antibody for the first 6-15 months of life. Only the $30-40 \%$ of these infants who are actually infected begin to make their own antibody to HIV and may go on to develop AIDS. The presence of HIV antibody is therefore not a reliable indicator of infection in children less than 15 months of age since the source of the antibody cannot be determined. If antibody persists beyond 15 months, however, the child should be assumed to be infected. Because one cannot easily differentiate HIV-infected infants from those with passive antibody, the anaesthetist should consider all children born to HIV-positive mothers as potentially infected. An assay to detect HIV proviral DNA sequences in infected lymphocytes (polymerase chain reaction or
TABLE II Paediatric AIDS classification: summary of current CDC critcria

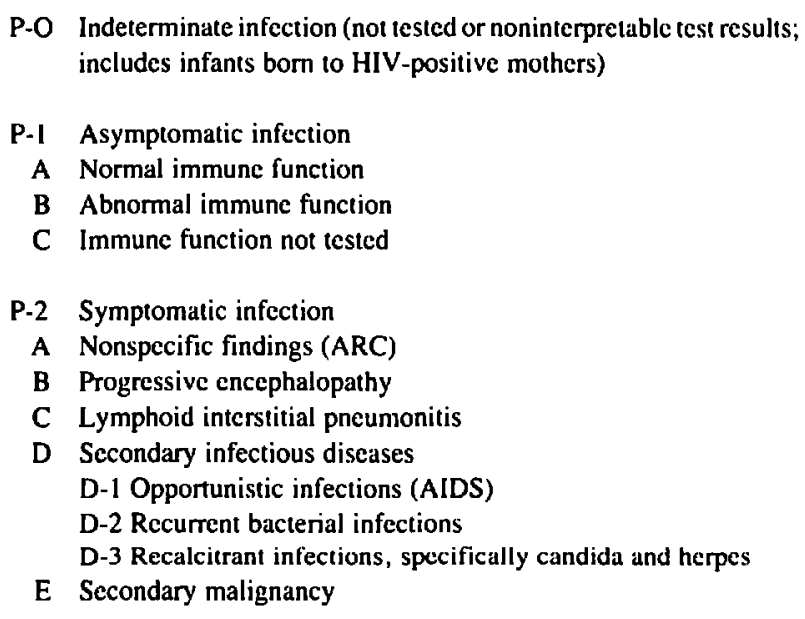

PCR) shows promise as a means of diagnosing HIV infection during early infancy. ${ }^{11}$

\section{Clinical manifestations}

The current CDC paediatric AIDS classification is shown in Table $11 .{ }^{12}$ The spectrum of infection in children spans asymptomatic infections on the one hand to severe, lifethreatening symptomatology on the other. (As in adults, a child does not meet CDC criteria as having "AIDS" by being infected with HIV alone - there must be some evidence of altered immune function and/or specific symptoms.)

In general, paediatric AIDS is a disease of early childhood with $50 \%$ of cases displaying clinical manifestations by one year of age and $80 \%$ by three years of age. The most common clinical features seen in these children are summarized below.

\section{Pulmonary}

Among HIV-infected children, pulmonary disease is the leading cause of morbidity and mortality. Offending infectious agents include the opportunistic pathogens Pneumocystis carinii, cytomegalovirus and Mycobacterium avium intracellulare - as well as the more typical paediatric bacterial and viral pathogens such as Streptococcus pneumoniae, Haemophilus influenzae and respiratory syncitial virus. Pneumocystis is a particularly virulent organism in these children. It appears that HIVinfected children with pneumocystis have a much poorer prognosis than their HIV-infected adult counterparts and that normal lymphocyte counts in children do not confer protection from this organism as has been shown in adults. $^{13}$

Aside from infectious pneumonias, children may also 
develop a more chronic form of lung disease termed lymphoid interstitial pneumonitis (LIP) or pulmonary lymphoid hyperplasia. Less common in adults with AIDS, LIP results in interstitial and peribronchiolar infiltration with lymphocytes and plasma cells. The exact aetiology of this disorder is unknown. The course is often slowly progressive and can lead to dyspnoea, bronchospasm and chronic hypoxia. Whereas infectious pneumonia may respond to specific antimicrobials, LIP is treated with steroids and bronchodilators. ${ }^{14}$

\section{Cardiac}

Cardiac disease is recognized with increasing frequency in HIV-infected children. ${ }^{15.16}$ Abnormalities include left and right ventricular dysfunction, pericardial effusions and dysrhythmias. One series investigating cardiovascular manifestations in 31 children infected with HIV found that $>90 \%$ had abnormal echocardiograms. Most children had hyperdynamic left ventricular function resulting from reduced afterload and increased contractility and approxiamtely one-third had diminished contractility. Other abnormalities found in this group were pericardial effusions, pericarditis, myocarditis and rhythm disturbances such as high-grade ectopy. Some children had exaggerated heart rate and blood pressure responses to medications, suggesting the presence of an autonomic neuropathy. ${ }^{17}$ Cardiac findings have been noted in children with both asymptomatic HIV infection and advanced AIDS as well as in those with and without specific cardiac symptoms. A cardiac evaluation should therefore be a routine part of the care of HIV-infected children. The HIV directly infects cardiac myocytes. ${ }^{18}$

\section{Neurological}

The majority of children infected with HIV have neurological abnormalities. ${ }^{19,20}$ Most have a progressive encephalopathy and show signs of developmental delay, progressive motor dysfunction (spasticity, pseudobulbar signs, movement disorders, cerebellar signs), loss of milestones and behavioural changes. Poor brain growth, as evidenced by microcephaly, is sometimes seen. Neuropathological features in these children include cerebral atrophy, ventriculomegaly and calcific vasculopathy of the basal ganglia. It is believed that the brain is primarily infected with HIV, since viral particles can be isolated in brain macrophages and multinucleated cells, as well as in CSF. A less severe, static encephalopathy has also been described in HIV-infected children who display nonprogressive cognitive and motor impairment. Children with progressive encephalopathy have a very poor prognosis.

Other neurological complications associated with HIV infection in children include primary central nervous system lymphomas and an increased incidence of stroke and serious bacterial infections including meningitis. ${ }^{20}$ Opportunistic infections of the central nervous system are reported but are not as common as in adults.

\section{Renal}

The renal changes in children with HIV appear to be similar to those in infected adults. ${ }^{21.22}$ Between 5 and $10 \%$ develop nephrotic signs (proteinuria, hypoalbuminaemia, oedema) and on microscopic analysis display focal glomerulosclerosis or mesangial hyperplasia. Some children progress to severe renal failure. Deposition of circulating immune complexes may be involved in the pathogenesis of this disorder.

\section{Gastrointestinal}

Children with HIV infection often fail to thrive. This results from chronic infectious diarrhoea and from mucocutaneous candidiasis which occurs in $75 \%$ of these children. Hepatosplenomegaly and hepatitis are other GI manifestations of HIV infection.

\section{Infectious}

Infectious complications in the HIV-positive child have already been alluded to in the discussion of other organ systems. The virus itself can infect many tissues but is most destructive in the brain and heart. Bacterial infections are common and recurrent and include otitis media, cellulitis, urinary tract infections, osteomyelitis, pneumonia, meningitis and sepsis. The causative agents are the usual pathogens in the paediatric population: $S$. pneumoniae, H. influenzae and Salmonella. Opportunistic infections with pneumocystis, cytomegalovirus, mycobacterium, herpes and candida also occur and can result in pneumonitis, hepatitis, enteritis and oesophagitis.

\section{Haematological}

Haematological abnormalities in the HIV-infected child can result in the depression of all cell lines. Anaemia may be secondary to primary marrow failure, "chronic disease," malnutrition and drug effects (AZTZidovudine). An autoimmune process similar to ITP has been described and may cause significant thrombocytopenia. Lymphopenia can be a dirct result of HIV infection while use of AZT and trimethaprim-sulfamethoxazole (Bactrim) may lead to neutropenia. ${ }^{23}$

\section{Non-specific manifestations}

Lymphadenopathy is a common presenting feature in the HIV-positive child. Enlarged parotid glands and craniofacial dysmorphic features (AIDS embryopathy) have also been described. ${ }^{24}$

It is difficult to make generalizations on the prognosis 
TABLE III Surgery on 20 children in Boston City Hospital 's Pediatric AlDS Program since 1987

\begin{tabular}{lc}
\hline Surgical procedure & Number \\
\hline Central venous catheter & 11 \\
Gastrostomy tube & 8 \\
Lung biopsy & 5 \\
Bronchoscopy & 3 \\
Lymph node, rectal or liver biopsy & 5 \\
Myringotomy tube insertion & 2 \\
Other & $\frac{4}{38}$ \\
Total & \\
\hline
\end{tabular}

of the HIV-infected child. While some children succumb very quickly to an initial life-threatening illness, others, with comprehensive medical support survive into later childhood. One group recently reported an overall 38month median survival for 172 children with perinatally aquired HIV infection. ${ }^{25}$ It appears from this group as well as others that poor prognostic indicators in children include early presentation, Pneumocystis carinii pneumonia and progressive encephalopathy while late presentation ( $>$ one year of age) and lymphoid interstitial pneumonitis confer a more favourable prognosis. ${ }^{25-27}$ Since some children with perinatally aquired infection have remained asymptomatic for up to ten years, some clinicians speculate that paediatric AIDS is a heterogenous disorder, dependent upon genetic factors, viral strains and other cofactors. ${ }^{26}$ With advances in clinical care including antiretrovirals and aggressive antibiotic and nutritional support, overall prognosis, though poor, has improved.

\section{Surgical interventions}

Approximately one-fifth of all patients with HIV infection undergo surgery sometime during the course of their illness. ${ }^{28}$ In adults, three common operations are lymph node biopsy, splenectomy and partial colectomy. In children, therapeutic (placement of central venous catheters, gastrostomy tubes) and diagnostic procedures (lung and liver biopsy) predominate. As HIV treatment modalities improve, however, more children can be expected to live longer and require common paediatric surgical procedures such as myringotomy, tonsillectomy and herniorraphy. At Boston City Hospital we have recently noted several HIV-positive children with dental caries severe enough to warrant oral surgery.

The Pediatric AIDS Program at Boston City Hospital has evaluated 176 children since 1987 and actively follows 90 . Thirty-eight operations were performed on 20 children and are listed in Table III. This does not include invasive procedures (endoscopy, bone marrow biopsy) performed outside the operating room which sometimes
TABLE IV Operative procedures in HIV-infected children - May 1986-March 1988

\begin{tabular}{lc}
\hline Procedures & Number performed \\
\hline Central venous catheter placement & 23 \\
Open lung biopsy & 11 \\
Incision and drainage soft tissue abcess & 6 \\
Incision and drainage perireclal abcess 4 & 3 \\
Myringotomy & 3 \\
lnguinal and umbilical hemia repair & 2 \\
Diverting colostomy & 1 \\
Nissen fundoplication & $\frac{1}{54}$ \\
Colostomy closure & 5 \\
Total & \\
\hline
\end{tabular}

necessitated the presence of an anaesthetist for analgesia or sedation. Beaver et al. recently published their surgical experience in HIV-infected children (Table IV). ${ }^{29}$

\section{Anaesthetic considerations}

As with any child suffering from a chronic illness, anaesthetic preparation begins with a thorough preoperative evaluation. While obtaining pertinent history and examining the child, the anaesthetist should be aware of the damage HIV can cause to almost every organ system. During the initial chart review, the child's baseline status is ascertained as well as recent illnesses related to HIV (episodes of pneumonia, LIP, renal failure, etc). Medications currently being taken may impact on drugs given in the operating room. Children with LIP receiving chronic steroid therapy, for example, may need steroid coverage during surgery. Current medications may also cause deleterious side-effects that could impact on anaesthetic care (Table V). ${ }^{30,31}$ Laboratory values to assess baseline haematological, hepatic and renal function should be checked preoperatively. A recent echocardiogram and ECG are helpful to determine the degree of cardiac dysfunction and may be sought in the child's outpatient records. If none is available and the child displays signs and symptoms of cardiac failure, consideration should be given to a formal cardiac evaluation before anaesthesia. A recent chest $\mathrm{X}$-ray can give valuable clues to pulmonary as well as cardiac involvement.

On physical examination, a thorough documentation of pre-existing neurological abnormalities allows postoperative dysfunction to be compared with a baseline. Attention is also directed to examination of the child's lungs (bronchospasm, often present with LIP, may respond to bronchodilators), heart and airway (parotitis, mandibular/ cervical adenopathy). In children with oral thrush, oesophagitis may be present with concomitant gastroesophageal reflux. This may warrant a rapid sequence induction of anaesthesia. In addition, tracheal intubation 
TABLE V Medications in the HIV-infected child

\begin{tabular}{|c|c|c|}
\hline Drug & Indication & Toxicity \\
\hline $\begin{array}{l}\text { AZT } \\
\text { (retrovir, } \\
\text { zidovudine) }\end{array}$ & Antiretroviral & $\begin{array}{l}\text { Anaemia, neutropenia, } \\
\text { thrombocytopenia. myopathy } \\
\text { nausea, vomiting }\end{array}$ \\
\hline $\begin{array}{l}\text { ddC } \\
\left(2^{\prime}, 3^{\prime} \text { dideoxy- }\right. \\
\text { cytidine })\end{array}$ & Antiretroviral & $\begin{array}{l}\text { Neutropenia, thrombocytopenia, } \\
\text { peripheral neuropathy }\end{array}$ \\
\hline $\begin{array}{l}\text { Acyclovir } \\
\text { (zovirax) }\end{array}$ & Antiviral (Herpes simplex) & $\begin{array}{l}\text { Renal failure, marrow suppression, } \\
\text { encephalopathy, abnormal LFTs }\end{array}$ \\
\hline $\begin{array}{l}\text { Ganciclovir } \\
\text { (DHPG) }\end{array}$ & Antiviral (CMV) & $\begin{array}{l}\text { Neutropenia, thrombocytopenia, } \\
\text { hypotension, nausea, vomiting, } \\
\text { renal failure, abnormal LFTs }\end{array}$ \\
\hline $\begin{array}{l}\text { Bactrim } \\
\text { (trimethaprim- } \\
\text { sulfamethoxazole) }\end{array}$ & $\begin{array}{l}\text { Pneumocystis carinii } \\
\text { pneumonia (treatment, } \\
\text { prophylaxis) }\end{array}$ & Fever, rash, marrow suppression \\
\hline Pentamidine & $\begin{array}{l}\text { Pneumocystis carinii } \\
\text { pneumonia (treatment, } \\
\text { prophylaxis) }\end{array}$ & $\begin{array}{l}\text { Renal failure, hypotension, } \\
\text { hypoglycacmia, marrow suppression, } \\
\text { abnormal LFTs, rash, bronchospasm } \\
\text { (nebulized) }\end{array}$ \\
\hline Dapsone & $\begin{array}{l}\text { Pneumocystis carinii } \\
\text { pncumonia (prohGylaxis) }\end{array}$ & $\begin{array}{l}\text { Rash, haemolytic anacmia, } \\
\text { nephrotic syndrome }\end{array}$ \\
\hline Amphoteracin B & Antifungal & $\begin{array}{l}\text { Renal failure, hypokalacmia, } \\
\text { anacmia, nausea, vomiting, fever, } \\
\text { chills }\end{array}$ \\
\hline Ketoconazole & Antifungal & $\begin{array}{l}\text { Nausea, vomiting, hepatitis, } \\
\text { thrombocytopenia }\end{array}$ \\
\hline
\end{tabular}

in an immunocompromised child with oral thrush may increase the risk of deeper and more invasive fungal infections. If the child is in an ICU with an intubated trachea, the tube size and its position are checked. It is good practice for the anaesthetist to accompany the child from the ICU to the OR to assure airway control and adequate ventilation.

Obtaining consent for anaesthesia may not be straightforward. Many of these children have complex social situations and are often in the care of people other than their biological parents. In general, we try to establish who has legal guardianship before obtaining consent. (The child's "legal guardian" may be an adoptive parent or the Department of Social Services.) Foster partents and case workers accompanying the child may not be empowered to give consent for anaesthesia, and a court order may be necessary. Questions on consent should be directed to the hospital legal staff.

Universal precautions are the standard in all ORs, ICUs and emergency rooms. Because of the potential risk of blood-borne infection, the anaesthetist should proceed with caution when administering every anaesthetic or performing any procedure regardless of HIV status. It is essential to wear gloves, protective eye wear and masks in the $O R$ and to dispose of needles and syringes safely. The risk of occupationally acquired HIV infection is very low but not zero. Following needle puncture from an HIVpositive patient, the incidence of seroconversion is approximately $0.5 \% .^{32}$

The psychological needs of the HIV-infected child and its family are important concerns for the anaesthetist. The same playful yet reassuring care we provide to all children is particularly important to these patients. Children with HIV infection should not be segregated from other patients in the preoperative holding area or in the post-anaesthesia care unit. Protective clothing (gloves, goggles, masks), while very important in the OR, may lead to feelings of stigmatization if worn elsewhere. It should be kept in mind at all times that HIV is not transmitted by casual contact.

Recommendations from the HIV anaesthesia literature on OR equipment preparation and usage are applicable to the paediatric patient. There is no evidence that HIV is spread by the respiratory route and the virus appears to be very sensitive to a wide range of disinfectants. Nevertheless, there are several points which are discomforting to 
the anaesthetist concerned with the potential contamination of anaesthesia machines: (1) HIV has been isolated in saliva, (2) respiratory and oral secretions may become mixed with blood (especially after a difficult tracheal intubation) and (3) HIV can be recovered at room temperature from both both dry and aqueous environments for between three and seven days. ${ }^{33.34}$ To combat the potential hazard of viral contamination, disposable breathing circuits are recommended whenever possible. The Mapleson D-type circuits such as the Bain System are particularly well suited for paediatric cases, since the $\mathrm{CO}_{2}$ absorber and one-way valves are taken out of the system entirely, thereby decreasing the risk of contamination. When a circle system is preferred disposable soda lime absorbers and anaesthetic circuits can be used instead. Bacterial filters may be used to further protect ventilators, $\mathrm{CO}_{2}$ absorbers and one-way valves from viral contamination. ${ }^{35}$ Filters may, however, increase airway resistance to dangerous levels, and so caution should be exercised. ${ }^{36}$ Reusable equipment such as laryngoscopes, face masks and temperature probes are cleaned and sterilized in the usual way (some groups use disposable laryngoscopes). ${ }^{37}$ The surface of the anaesthetic machine should be cleaned with a dilute bleach solution after the conclusion of an HIV-infected case. Scavenging systems appear not to be important as potential sources of viral contamination. ${ }^{35}$

The choice of anaesthetic agents for the HIV-infected child should take into consideration the degree of endorgan damage present. For example, if the patient has Pneumocystis carinii pneumonia with impaired alveolar gas exchange, then a technique with high inspired oxygen concentrations is needed, ${ }^{37}$ while high doses of volatile anaesthetics should probably be avoided if there is evidence of hypodynamic ventricular function. Narcotics and muscle relaxants are chosen and dosed according to alterations in renal and hepatic function. Cannulae placed during the course of an anaesthetic should be done with strict attention to asepsis, keeping in mind the child's underlying immuno-deficiency.

Although general anaesthesia is the technique most often chosen in paediatric practice, regional anaesthesia deserves consideration. It has been suggested that depression of cell-mediated immunity following general anaesthesia does not occur after spinal or epidural techniques. ${ }^{28,38}$ The alterations in immune function after general anaesthesia include natural killer cell activity, T-lymphocyte subpopulations, lymphocyte blastogenic responses and monocyte and neutrophil activity. However, at best the immunological advantages of regional anaesthesia in the HIV-infected patient is theoretical. The studies cited were all performed on healthy immunocompetant adults and it is difficult to separate out the immunological effects of anaesthesia from those of surgery. In addition, the alterations in immune function noted were transient (several hours) and did not result in infectious complications after operation. Clearly, more research is required before recommending regional to general anaesthesia in the HIV-infected population on an immunological basis alone. There are situations where regional anaesthesia offers advantages - in the child with chronic LIP and bronchospasm, for example, where intubation is best avoided. Some have suggested that preoperative focal neurological deficits constitute a relative contraindication to this technique. ${ }^{39}$

The maintenance of patient confidentiality while in the OR is a right which the anaesthetist and other health care providers must respect. Recently at one of our institutions, it was noted that, on a copy of the day's OR schedule posted in the anaesthesia workroom, a patient's name was circled and an arrow drawn pointing to the word "AIDS" presumably to indicate a need for special equipment. While it is the obligation of the anaesthetist to disclose a patient's HIV status to those who have a legitimate need to know - OR and recovery room personnel ${ }^{40}$ - ethical standards demand discretion and common sense. Care must be taken to avoid incidents which, although wellintentioned, violate the patient's right to privacy.

\section{ICU management}

Recent reviews in the paediatric and critical care literature paint a grim picture for the HIV-infected child hospitalized in a paediatric intensive care unit (PICU). More of these children are admitted to PICUs, primarily because of acute respiratory failure (ARF) - $48 \%$ of all paediatric AIDS admissions according to one group followed by cardiovascular disease $(23 \%)$, central nervous system diseases (11\%), GI disease $(4 \%)$ and after elective surgery $(14 \%){ }^{41}$ The same group found that half of these children were first diagnosed with AIDS during their PICU stay. Therefore, infection with HIV must be in the differential diagnosis for any child with unexplained respiratory, cardiovascular or neurologic symptoms. Mortality rates for paediatric AIDS patients with acute respiratory failure were $81 \%$ and $84 \%$ in two PICUs. ${ }^{42,43}$ Pneumocystis and cytomegalovirus as well as bacterial pathogens such as pseudomonas and other gram-negative organisms were important causes of ARF.

At Boston City Hospital, 21 children have been admitted to the PICU since 1987 (32 total admissions - see Table VI). Fourteen are still alive. The ethical dilemma of providing expensive life-saving care for children with a very poor prognosis will not be addressed here. We can, however, point to several long-term survivors who are leading fulfilling lives as a case against the supposed "futility" of treating these children in an ICU.

When AIDS is either known or suspected in a child with 
TABLE VI PICU admissions in 21 children in Boston City Hospital's Pcdiatric AIDS Program since 1987

\begin{tabular}{lc}
\hline Admission diagnosis & Number \\
\hline Respiratory distress & 14 \\
Liver failure & 3 \\
Infectious disorders & 4 \\
Diarrhoca/dehydration & 2 \\
Postoperative complications & 5 \\
Other & 4 \\
Total & 32 \\
\hline
\end{tabular}

respiratory failure, a cardiac evaluation with an echocardiogram may help distinguish infectious pneumonitis from alveolar disease secondary to ventricular dysfunction. Central line placement can present a problem because of hypertrophied lymp nodes in the neck and groin. The approach to the subclavian vein usually provides the best landmarks and is generally free of obstructive lymph nodes but carries the risk of pneumothorax, particularly when the trachea is intubated and using high-pressure ventilation. Guildelines concerning universal precautions and equipment are similar to those described for management in the OR.

\section{Conclusion}

There is, perhaps, nothing sadder about the AIDS epidemic than the infants and children who are affected by it. As their numbers grow, anaesthetists will care for them with increasing frequency both in the $\mathrm{OR}$ and the ICU. We have reviewed some of the pathophysiological changes that occur in HIV-infected children as well as management issues in the OR and ICU. Anaesthetists and other health care professionals must continue to learn about the manifestations of HIV infection to provide competent and compassionate care.

\section{Acknowledgment}

The authors (DS and TS) dedicate this paper to the memory of Risa Schwartz.

\section{References}

1 Ginsburg HM, Trainer J, Reis E. A review of cpidemiologic trends in HIV infection of women and children. Pediatric AIDS and HIV Infection: Fetus to Adolescent 1990; 1: 11-5.

2 Koop CE. Excerpt from keynote address. In: Report of Surgeon General's Workshop on Children with HIV Infection and Their Families. DHHS publication No. HRSD-MC 87-1, 1987, 3-5.

3 Kunkel SE, Warner MA. Human T-cell lymphotropic virus type III (HTLV-III) infection: how it can affect you, your patient and your anesthesia practice. Anesthesiology 1987; 66: 195-207.

4 Greene ER. Acquired immunodeficiency syndrome: an overview for anesthesiologists. Anesth Analg 1986; 65: 1054-8.

5 Lee $K G$, Soni $N$. AIDS and anaesthesia. Anaesthesia 1986; 41: 1011-6.

6 Warner MA, Kunkel SE. Human imnunodeficiency vinus infection. Anesthesiology Clinics of North America 1989; 35: 795-811.

7 Cordero AS, Bonner JT, Brynes RK. AIDS and the anaesthetist. Can Anaesth Soc J 1985; 32: 45-8.

8 Berry $A J$, Katz $J D$. Hazards of working in the operating room. In: Barash PG, Cullen BF, Stoelting RK (Eds.).

Clinical Anesthesia Ist ed., Philadelphia: J.B. Lippincott Co. $1989 ; 81-2$.

9 Katz J. Anesthesia and Uncommon Pediatric Diseases. 1st ed., W.B. Saunders Company, 1987; 441-3.

10 Cooper ER, Pelton SI, LeMay M. Acquired immunodeficiency syndrome: A new population of children at risk. Pediatr Clin North Am 1988; 35: 1365-87.

11 Husson RN, Comeau AM, Hoff $R$. Diagnosis of human immunodeficiency virus infection in infants and children. Pediatrics 1990; 86: 1-10.

12 CDC. Classification system for human immunodeficiency virus infection in children under 13 years of age. MMWR 1987; 36: 593.

13 Leibovitz E, Rigaud M, Pollack $H$ et al. Pneumocystis carinii pneumonia in infants with the human immunodeficiency virus with more than $450 \mathrm{CD} 4 \mathrm{~T}$-lymphocytes per cubic millimeter. N Engl J Med 1990; 323: 531-3.

14 Rubinstein A, Bernstein LJ, Charytan M, Krieger BZ, Ziprkowski $M$. Cortico-steroid treatment for pulmonary lymphoid hyperplasia in children with the acquired immune deficiency syndrome. Pediatric Pulmonology 1988; 4: 13-7.

15 Steinherz LJ, Broochstein JA, Robins J. Cardiac involvement in congenital acquired immunodeficiency syndrome. Am J Dis Child 1986; 140: 1241-4.

16 Medlock MD, Tilleli JT, Pearl GS. Congenital cardiac toxoplasmosis in a newbom with acquired immunodeficiency syndrome. Pediatr Infect Dis J 1990; 9: 129-32.

17 Lipshultz SE, Chanock S, Sanders SP, Colan SD, PerezAtayde A, McIntosh K. Cardiovascular manifestations of human immunodeficiency virus infection in infants and children. Am J Cardiol 1989; 63: 1489-97.

18 Grody $W W$, Cheng L, Lewis $W$. Infection of the heart by the human immunodeficiency virus. Am J Cardiol 1990; 66: 203-6.

19 Epstein LG, Sharer LR, Goudsmit J. Neurologic and neuropathologic features of human immunodeficiency virus infection in children. Ann Ncurol 1988; 23(supp): 519-23. 
20 Belman AL. Neurologic manifestations of HIV infection in children. In: The Implications of AIDS for Mothers and Children, ACTS, International Conference, Paris, Nov. 1989; 177-91.

21 Strauss J, Abitbol C, Zilleruelo $G$ et al. Renal disease children with the acquired immunodeficiency syndrome. N Engl J Med 1989; 321: 627-9.

22 Connor E, Gupta S, Joshi $V$ et al. Acquired immuno deficiency syndrome - associated renal disease in children. J. Pediatr 1988; 113: 39-44.

23 Phillips AJ, Spence AA. Zidovudine and the anaesthetist. Anaesthesia 1987; 42: 799- 800 .

24 Marion RW, Wiznia AA, Hutcheon $G$, Rubinstein $A$. Human T-cell lymphotropic virus Type III (HTLV-III) embryopathy: a new dysmorphic syndrome associated with intrautcrine HTLV-IIl infection. Am J Dis Child 1986; 140: 638-40.

25 Scott $G B$, Hutto C, Makuch $R W$ et al. Survival in children with perinatally acquircd human immunodeficiency virus type 1 infection. N Engl J Med 1989; 321L1721-6.

26 Pisso PA. Pediatric AIDS: problems within problems. J Infect Dis 1990; 161: 316-25.

27 Bernstein LJ, Bye MR, Rubinstein A. Prognostic factors and life expectancy in children with acquired immunodeficiency syndrome and pneumocystis carini pneumonia. Am J Dis Child 1989; 143: 775-8.

28 Scannel KA. Surgery and human immunodeficiency virus discase. J Acquir Immune Defi Syndr 1989; 2: 43-53.

29 Beaver BL, Hill JL, Vachon DA et al. Surgical intervention in children with human immunodeficiency virus infection. J Pediatr Surg 1990; 25: 79- 84.

30 Bartlett J. Pocketbook of Infectious Disease Therapy 1989-1990. Williams and Wilkins, Baltimore 1990; 43-52.

31 Williams I, Mindel A, Weller I. AIDS. Philadelphia: J.B. Lippincott. 1989; 92-103.

32 Marcus $R$. CDC Cooperative Necdlestick Surveillance Group. Surveillance of healch care workers exposed to blood from patients infected with the human immunodeficiency virus. N Engl J Med 1988; 319: 1118-23.

33 Resnick L, Veren $K$, Salahuddin SZ, Tondreau $S$, Markham $P D$. Stability and inactivation of HTLVIII/LAV under clinical and laboratory environments. JAMA 1986; 255: 1887-91.

34 McDougal JS, Martin LS, Cort SP, Mozen M, Heldebrant $C M$, Evatt $B L$. Thermal inactivation of the acquired immunodeficiency syndrome virus, human $T$ lymphotropic virus-III/ lymphadenopathy-associated virus, with special reference to antihemophilic factor. J Clin Invest 198576 : 875-7.

35 Browne RA, Chernesky MA. Infectious diseases and the Anaesthetist. Can J Anaesthetist. Can J Anaesth 1988; 35: 655-65.
36 Dorsch JA, Dorsch SE. Understanding Ancsthesia Equipment 2nd cd. Baltimore: Williams andWilkins, 1984; 222-3.

37 Arden J. Anesthetic management of patients with AIDS (Letter). Anesthesiology 1986; 64: 660-1.

38 Stevenson $G W$, Hall $S C$, Rudnick $S$, Seleny $F L$, Stevenson $H C$. The effect of anesthetic agents on the human immune response. Anesthesiology 1990; 72: 542-52.

39 Greene ER. Spinal and cpidural anesthesia in patients with acquired immunodeficiency syndrome. Ancsth Analg 1986; 65: 1089-93.

40 Dickens $B M$. Legal limits of AIDS confidentiality. JAMA 1988; 259: 3449-51.

41 Wilkinson JD, Greenwald BM. The acquired immunodeficiency syndrome: impact on the pediatric intensive carc unit. Crit Care Clin 1988; 4: 831-44.

42 Notterman DA, Greenwald BM, Di Maio-Hunter $A$. Wilkinson JD, Krasinski K, Borkowsky W. Outcome after assisted ventilation in children with acquired immunodeficiency syndrome. Crit Care Med 1990: 18: 18-20.

43 Vernon $D D$, Holzman BH, Lewis $P$, Scott GB, Birriel JA, Scott $M B$. Respiratory failure in children with acquired immunodeficency syndrome and acquired immunodeficiency syndrome-related complex. Pediatrics 1988; 82: 223-8. 